\title{
Grevisto
}

\section{ACESSO À INFORMAÇÃO COMO FERRAMENTA DE COMBATE À CORRUPÇÃO POR JORNALISTAS INVESTIGATIVOS}

ACCESS TO INFORMATION AS ANTICORRUPTION TOOL FOR INVESTIGATIVE JOURNALISTS

EL ACCESO A LA INFORMACIÓN COMO HERRAMIENTA DE LUCHA DE LOS PERIODISTAS DE INVESTIGACIÓN CONTRA LA CORRUPCIÓN

\section{Veronica Rufino Sousa ${ }^{1}$ \\ Pedro Benevides ${ }^{2,3}$}

\section{RESUMO}

Criada com o objetivo de tornar acessíveis informações de interesse público mantidas pelos governos, a Lei de Acesso à Informação (Lei 12.527/2011) possibilita maior acompanhamento das ações governamentais, facilitando a prestação de contas junto à sociedade. Para os jornalistas - principalmente os investigativos, o instrumento legal trouxe novas perspectivas para a apuração de informações, muitas vezes negadas por parte do governo. Este estudo tem o

\footnotetext{
1 Mestre em Jornalismo pela Universidade Federal da Paraíba (UFPB). Pós-Graduada em Marketing Avançado pelo IESP. Graduação em Comunicação Social - Jornalismo pela Universidade Federal da Paraíba (UFPB). E-mail: veronicamrsousa@gmail.com.

2 Doutor em Comunicação pela Universidade do Vale do Rio dos Sinos (Unisinos). Mestre em Comunicação e graduado em Jornalismo, ambos pela Universidade de Brasília (UnB). Professor do Curso de Jornalismo da Universidade Federal da Paraíba e do Programa de Pós-Graduação em Comunicação (UFPB). E-mail: pbenevides0@yahoo.com.br.

3 Endereço de contato dos autores (por correio): Instituto Federal de Educação, Ciência e Tecnologia da Paraíba, Reitoria. Avenida João da Mata, Jaguaribe, CEP: 58015-020 - João Pessoa, PB - Brasil.
} 


\section{Grevisto}

ISSN n² 2447-4266

Vol. 4, n. 2, Abril-Junho. 2018

DOI: http://dx.doi.org/10.20873/uft.2447-4266.2018v4n2p756

objetivo de analisar a aquisição de informações públicas por jornalistas investigativos no combate à corrupção, tomando como exemplo a série de reportagens do Programa Fantástico da Rede Globo, "Cadê o dinheiro que tava aqui".

PALAVRAS-CHAVE: Acesso à Informação; Jornalismo Investigativo; Corrupção.

\section{ABSTRACT}

Created with the aim of making accessible information of public interest held by governments, the Access to Information Act (Law 12,527 / 2011 ) enables closer monitoring of government actions, facilitating accountability to society. For journalists - especially investigative, legal instrument brought new perspectives to calculate information, often denied by the government. This study aims to examine the acquisition of public information for investigative journalists in combating corruption, taking as an example the series of reports Program Fantastic Globo, " Where's the money that was here."

KEYWORDS: Access to information; Investigative Journalism; Corruption.

\section{RESUMEN}

Creado con el objetivo de hacer accesible la información de interés público que tienen los gobiernos, la Ley de Acceso a la Información (Ley 12.527 / 2011) permite un control más estricto de las acciones del gobierno, lo que facilita la rendición de cuentas a la sociedad. Para los periodistas - en especial de investigación, instrumento jurídico trajo nuevas perspectivas para el cálculo de la información, a menudo negada por el gobierno. Este estudio tiene como objetivo examinar la adquisición de información pública para periodistas de investigación en la lucha contra la corrupción, tomando como ejemplo la serie de informes fantástico programa Globo, "¿Dónde está la tava dinero aquí." 


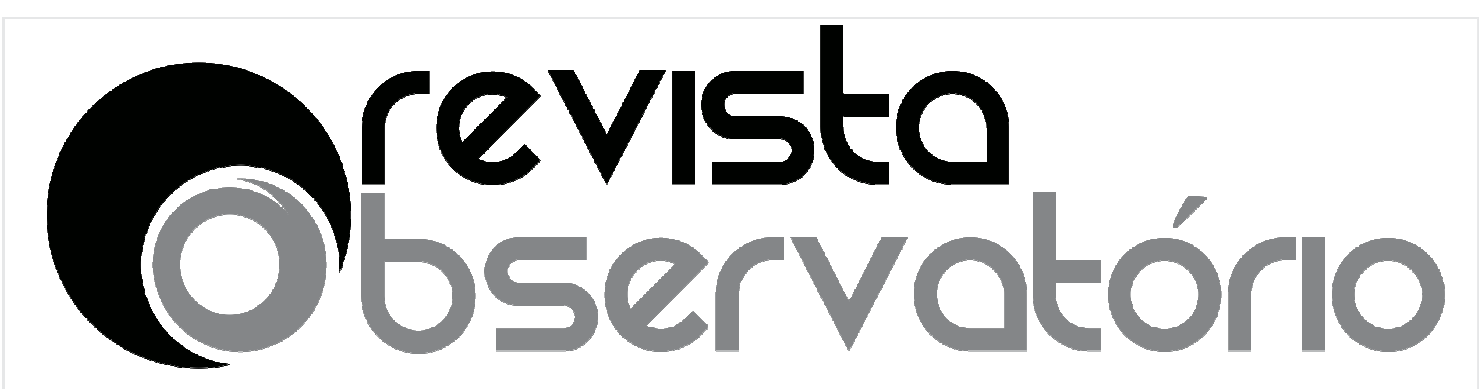

ISSN n² 2447-4266

Vol. 4, n. 2, Abril-Junho. 2018

DOI: http://dx.doi.org/10.20873/uft.2447-4266.2018v4n2p756

PALABRAS CLAVE: Acceso a la Información; periodismo de investigación; Corrupción.

Recebido em: 12.09.2017. Aceito em: 16.12.2017. Publicado em: 01.04.2018. 


\section{Grevisto}

ISSN n² 2447-4266

Vol. 4, n. 2, Abril-Junho. 2018

DOI: http://dx.doi.org/10.20873/uft.2447-4266.2018v4n2p756

\section{INTRODUÇÃO}

A Lei de Acesso à Informação (Lei 12.527/2011), que entrou em vigor a partir de 16 de maio de 2012, regulamenta o direito de acesso às informações públicas, possibilitando a qualquer cidadão o recebimento de informações públicas dos órgãos e entidades da Administração. Através da lei, a sociedade tem a oportunidade de acompanhar e avaliar as ações do governo, e exigir punições quando tais atos vão de encontro ao bem comum.

Os jornalistas, principalmente os investigativos, passam a contar com um novo instrumento para a apuração de informações, que muitas vezes são ocultadas pelo governo. Através da lei, estes profissionais têm assegurado o acesso a documentos e dados essenciais para o cumprimento do seu poder fiscalizador, de averiguar e apresentar situações que vão de encontro ao bem comum, como casos de transgressões legais e abusos de poder cometido por agentes públicos.

A série de reportagens do programa Fantástico (Rede Globo de Televisão) intitulada "Cadê o dinheiro que tava aqui?", produzida pelo jornalista Eduardo Faustini, demonstra bem a utilização de dados públicos para a abordagem de assuntos de interesse da população, como a corrupção e desvio de verbas por políticos e gestores públicos.

Este artigo analisa o acesso a informações públicas na reportagem exibida no referido programa, em 09 de novembro de 2014, que aborda fraudes de licitações nas áreas de saúde e educação, nas prefeituras de Crato e Juazeiro do Norte, no Ceará.

Para a concretização desta pesquisa foram utilizadas consultas bibliográficas que abordam temáticas referentes ao acesso à informação pública, Lei de Acesso à Informação e jornalismo investigativo, tais como Dutra (2015), Macet (1997), Lopes e Proença (2003), Aguiar (2006), Fortes (2005) e 


\section{Grevisto}

ISSN n² 2447-4266

Vol. 4, n. 2, Abril-Junho. 2018

DOI: http://dx.doi.org/10.20873/uft.2447-4266.2018v4n2p756

Sequeira (2005). Além disso, foram realizadas entrevistas, por uma das autoras deste artigo, com representantes dos órgãos públicos personagens da reportagem em foco, para compreender o repasse de informações (documentos, relatórios, vídeos, etc.) utilizadas na matéria.

\section{ACESSO À INFORMAÇÃO NO BRASIL}

Detentor de uma cultura de opacidade e patrimonialismo, o Brasil tem sua história marcada pela pouca participação popular nas decisões de governo. Dutra (2015) resgata períodos históricos do país - como o Império (1822-1889) marcado pelo ruralismo, predominância de latifúndios e da mão-de-obra escrava; e a instituição da República, em 1889 - período caracterizado, durante bom tempo, pelo coronelismo e pela desorganização dos serviços públicos para demonstrar o grande desafio de se desenvolver uma política voltada à transparência da administração pública.

Diante deste contexto, o Brasil foi o $89^{\circ}$ país a aprovar uma legislação voltada ao direito ao acesso à informação pública no mundo. A Constituição Federal (CF) de 1988 foi um grande marco para este acontecimento.

Promulgada num cenário de redemocratização após o período de Ditadura Militar, que durou de 1964 a 1985, a Constituição Cidadã trouxe avanços em todas as áreas, porém, diante da necessidade de devolver ao povo todos os direitos que haviam sido retirados deles durante o processo ditatorial, seu foco principal se voltou aos Direitos Fundamentais (DUTRA, 2015).

A Carta Magna apresenta diversas matérias ligadas ao acesso à informação. Na tabela abaixo, é exposta a base constitucional de cada artigo. 


\section{Grevisto}

ISSN n² 2447-4266

Vol. 4, n. 2, Abril-Junho. 2018

DOI: http://dx.doi.org/10.20873/uft.2447-4266.2018v4n2p756

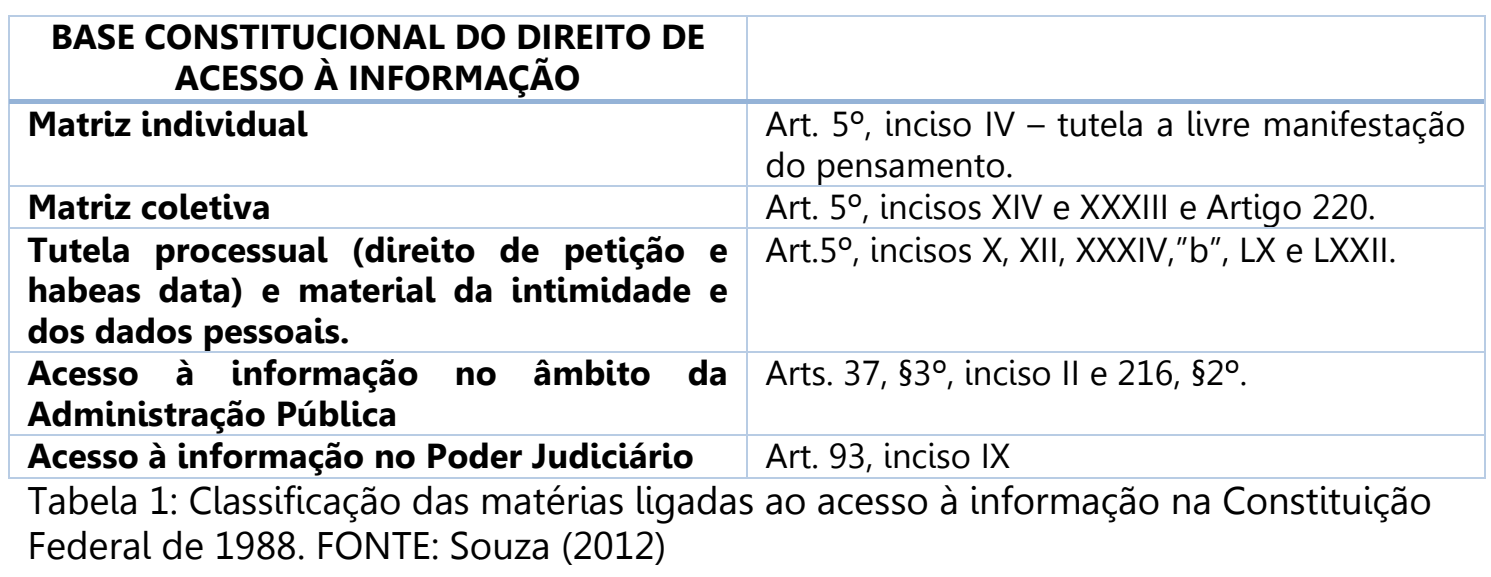
afirma:

Dentre os artigos elencados, destaque para o Artigo $5^{\circ}$, Inciso XXXIII, que

Todos têm direito a receber dos órgãos públicos informações de seu interesse particular, ou de interesse coletivo ou geral, que serão prestadas no prazo da lei, sob pena de responsabilidade, ressalvadas aquelas cujo sigilo seja imprescindível à segurança da sociedade e do Estado. (BRASIL, 1988)

Em seu Artigo 37, a CF/88 elenca a publicidade dos atos públicos como princípio da Administração Pública, e no Artigo 216, Parágrafo $2^{\circ}$, aborda a gestão de documentos governamentais pela administração.

Apesar de ser um marco para a constituição de políticas de acesso a informações no Brasil, a Carta Cidadã apenas institui o direito, deixando a responsabilidade de sua regulamentação ao legislador infraconstitucional. Assim, como afirma Rodrigues (2012, p.15) "se tornou essencial a regulamentação deste direito, visto que o texto constitucional, por si só, o apresenta de modo bastante vago" - regulamentação esta, que ocorreu somente com a efetivação da Lei de Acesso à Informação, em 2011.

Cabe destacar ainda as relevantes iniciativas de instituições que contribuíram para a efetivação do acesso à informação no Brasil. A 


\section{Qrevisto}

ISSN n² 2447-4266

Vol. 4, n. 2, Abril-Junho. 2018

DOI: http://dx.doi.org/10.20873/uft.2447-4266.2018v4n2p756

Controladoria Geral da União (CGU), por exemplo, que foi criada no ano de 2001, atuou no assessoramento relativo a questões como a defesa do patrimônio público e transparência da gestão.

Uma das principais ações do órgão foi a criação do Portal da Transparência ${ }^{4}$, que possibilita ao cidadão o acompanhamento da execução financeira dos programas do Governo Federal, disponibilizando informações sobre os recursos públicos federais transferidos, bem como dados sobre os gastos realizados pelo próprio Governo Federal em compras ou contrato de obras e serviços.

A CGU possui ainda a atribuição de monitorar a aplicação da Lei de Acesso à Informação e do Decreto $n^{\circ} 7.724$, que a regulamenta no Poder Executivo Federal, atuando ainda como instância recursal na esfera federal.

A Associação Brasileira de Jornalismo Investigativo (Abraji) $)^{5}$ foi outra instituição atuante em defesa do direito de acesso à informação pública. Em 2003, realizou o I Seminário Internacional sobre Direito de Acesso a Informações Públicas, que resultou no lançamento, um ano depois, do Fórum de Direito de Acesso a Informações Públicas.

De acordo com a Associação, os objetivos propostos pelo Fórum são:

1) Promover e incentivar o debate sobre direito de acesso a informações públicas no Brasil - e sobre temas correlatos, como alterações na lei de arquivos públicos.

2) Atuar sem conotação político-partidária nem fins lucrativos.

3) Defender uma lei que garanta e facilite o acesso do público no Brasil a documentos públicos produzidos pelos Três Poderes da República, bem como aos documentos de governos estaduais e municipais.

4) Desenvolver campanhas de divulgação a respeito da necessidade de uma lei de acesso a informações públicas no Brasil.

\footnotetext{
${ }^{4}$ Disponível em http://transparencia.gov.br/

${ }^{5}$ http://www.abraji.org.br/
} 


\section{Grevisto}

ISSN n² 2447-4266

Vol. 4, n. 2, Abril-Junho. 2018

DOI: http://dx.doi.org/10.20873/uft.2447-4266.2018v4n2p756

5) Defender que os governos, em todos os seus níveis, tenham a preocupação de corretamente arquivar qualquer documento público de forma a facilitar o seu acesso futuro, bem como de manter sistemas permanentes de gerenciamento e preservação desses documentos. Isso inclui também a unificação dos critérios de registros em cartórios e juntas comerciais de todo o país.

6) Desenvolver iniciativas voltadas para o tratamento, agregação e disseminação de informações em poder do Estado e sobre o Estado. ${ }^{6}$

\section{A Lei de Acesso à Informação: principais aspectos}

Sancionada pela presidente Dilma Rousseff em 18 de novembro de 2011, a Lei $N^{\circ} 12.527$ foi criada visando regular e garantir o acesso a informações disposto na Constituição Federal, conforme mencionado anteriormente.

O dispositivo legal, de acordo com Magalhães, Medeiros e Pereira (2014), é considerado amplo e progressista, criado como instrumento de combate à corrupção e de incentivo à transparência das ações dos gestores públicos de todos os órgãos da administração direta dos três poderes (Executivo, Legislativo e Judiciário), incluindo as Cortes de Contas e o Ministério Público, assim como autarquias, fundações e empresas públicas, sociedades de economia mista e demais entidades controladas direta ou indiretamente pela União, Estados, Distrito Federal e Municípios. As empresas privadas sem fins lucrativos que recebam recursos públicos também estão submetidas à lei.

Dentre os principais artigos destacados na Lei $12.527 / 2011$, o artigo $3^{\circ}$ elenca diretrizes que devem ser seguidas para assegurar o direito de acesso à informação, como:

I - observância da publicidade como preceito geral e do sigilo como exceção; II - divulgação de informações de interesse público, independentemente de solicitações; III - utilização de meios de comunicação viabilizados pela tecnologia da informação; IV - fomento ao desenvolvimento da cultura de transparência na administração

\footnotetext{
${ }^{6}$ Disponível em: < http://www.informacaopublica.org.br/?page id=2>
} 


\section{Grevisto}

ISSN n² 2447-4266

Vol. 4, n. 2, Abril-Junho. 2018

DOI: http://dx.doi.org/10.20873/uft.2447-4266.2018v4n2p756

pública; V - desenvolvimento do controle social da administração pública (BRASIL, 2011).

Os princípios mencionados evidenciam a preocupação de estimular uma cultura de amplo acesso a informações na administração pública brasileira.

$O$ acesso defendido pela lei engloba registros, documentos, orientações sobre procedimentos de acessibilidade, informações sobre políticas, organização, programas, projetos e serviços realizados por órgãos e entidades; assim como relativas à administração do patrimônio público, utilização de recursos, licitação e contratos administrativos, bem como de procedimentos e auditorias internas.

A Lei de Acesso também estabelece a objetividade e clareza da linguagem em que a informação for transmitida - visando a sua fácil compreensão, assim como a agilidade na transmissão desses dados.

Cabe ressaltar ainda que a rede mundial de computadores (Internet) é tratada pela lei como meio obrigatório de divulgação e o acesso às informações é permitido a qualquer cidadão interessado que seja identificado e especifique o dado solicitado.

De acordo com a cartilha da Controladoria Geral da União, as restrições ao acesso englobam dados pessoais e informações que foram classificadas como sigilosas. Informações sob a guarda do Estado que dizem respeito à intimidade, honra e imagem das pessoas, por exemplo, não são públicas (ficando protegidas por um prazo de cem anos). Elas só podem ser acessadas pelos próprios indivíduos e, por terceiros, apenas em casos excepcionais previstos na Lei. (CGU, 2011) 


\section{Obsevisto}

ISSN n² 2447-4266

Vol. 4, n. 2, Abril-Junho. 2018

DOI: http://dx.doi.org/10.20873/uft.2447-4266.2018v4n2p756

\section{Lei como instrumento de apuração de informações públicas}

Magalhães, Medeiros e Pereira (2014), em estudo abordando a relação entre a Lei de Acesso e o combate à corrupção, avaliam positivamente o instrumento como ferramenta importante para a efetivação da democracia e o combate à corrupção no Brasil. Porém, ressalvam que,

embora o acesso à informação pública não seja suficiente para o
combate à corrupção, mostra-se uma medida indispensável para a
promoção de uma consciência cidadã. Outros mecanismos de
participação mostram-se essenciais e complementares, tais como a
criação de fóruns locais e desenvolvimento de uma cultura
participativa na formulação de políticas públicas. (MAGALHÃES ET. AL,
2014, p. 71)

A Lei de Acesso à informação além de proporcionar maior possibilidade de acompanhamento das ações governamentais por parte do povo, promovendo a democracia, se torna, para o jornalista, um novo mecanismo de trabalho, no tocante à apuração de informações.

Em 2015, a pesquisadora Dutra realizou um estudo enfocando a utilização do instrumento legal como subsídio para a produção de notícias nos jornais Folha de S. Paulo, O Estado de S. Paulo e O Globo, durante o primeiro ano de vigência da Lei (2012/2013). Segundo a autora,

Em relação ao uso da LAI no trabalho, de modo geral, os jornalistas têm utilizado a Lei na produção de matérias de fôlego, que possuem um prazo maior, uma vez que estão cientes do tempo que pode levar até obter a informação desejada. Assim, os profissionais continuam recorrendo às assessorias de imprensa ou diretamente às fontes para produção do noticiário diário, ou hard news. (DUTRA, 2015, p.121)

Os jornalistas entrevistados por Dutra para a realização da pesquisa, também elencaram os pontos positivos e negativos da Lei para o trabalho de apuração de informações públicas.

Como aspectos negativos, destacam-se: 


\section{Obevisto
Obervatório}

ISSN n² 2447-4266

Vol. 4, n. 2, Abril-Junho. 2018

DOI: http://dx.doi.org/10.20873/uft.2447-4266.2018v4n2p756

a ausência de indicação de organismos responsáveis pelo atendimento à lei, as amplas possibilidades de negativas que deveriam ser mais específicas, o fato da Lei não prever a participação da sociedade civil nas instâncias recursais, a não criação de uma entidade recursal autônoma. (DUTRA, 2015, p. 111)

Outras observações dizem respeito ao descumprimento da Lei em alguns órgãos federais, arbitrariedade relativa à classificação de documentos, custos para reprodução de arquivos e a dificuldade na decodificação de informações.

Em relação aos pontos positivos, a pesquisadora elenca:

o parágrafo único do art. 21, que determina a impossibilidade de sigilo quanto a fatos relativos à violação de direitos humanos, e o parágrafo quarto do art.31, que estabelece que não pode haver restrição de acesso à informações essenciais para recuperação de fatos históricos de maior relevância (...) Outro ponto positivo lembrado pelos entrevistados foi a divulgação obrigatória dos salários dos servidores de órgãos públicos de maneira ativa, sem a necessidade de solicitação. Apesar do texto da Lei não prever essa obrigatoriedade, ela foi adotada nas posteriores regulamentações nos Três Poderes. (DUTRA, 2015, p. 111)

A autora conclui destacando a importância da Lei para o amadurecimento da democracia brasileira e considerando que alguns aspectos culturais ainda restringem $\mathrm{o}$ acesso às informações públicas e, consequentemente, o trabalho do jornalista. De acordo com Dutra (2015, p. 122), "para que a estrutura do Estado opere de maneira adequada, superando as tradições de opacidade do poder e construindo uma cultura da transparência, é necessário um comprometimento por parte das autoridades e por parte da sociedade".

\section{JORNALISMO COMO PODER FISCALIZADOR}

Até a segunda metade do Século XIX, as práticas jornalísticas estiveram associadas a representações políticas, sendo verdadeiramente vozes dos 


\title{
Obevisto
Obervatório
}

ISSN n² 2447-4266

Vol. 4, n. 2, Abril-Junho. 2018

DOI: http://dx.doi.org/10.20873/uft.2447-4266.2018v4n2p756

partidos políticos. A partir da industrialização, ampliação de direitos sociais e a diminuição do analfabetismo - que trouxe como consequência a ampliação do seu público - o jornalismo se desenvolve, passando a adquirir outros valores.

O formato de divulgação de cenários políticos é substituído por um jornalismo informativo, com o surgimento, por exemplo, dos penny press ${ }^{7}$ nos Estados Unidos, marcados pela incansável busca pela objetividade ${ }^{8}$. 0 surgimento desta imprensa "independente" traz consigo uma nova visão do profissional.

A noção do jornalismo como Quarto Poder nasce neste contexto, legitimado pelas teorias democráticas que destacam a atuação jornalística como provedor de informações essenciais para tornar opinião pública politicamente esclarecida. Assim, a liberdade da imprensa passa a ser necessária à efetivação da democracia.

Ao explanar as teorias democráticas, Traquina aborda o papel duplo do jornalismo de:

\begin{abstract}
vigiar o poder político e proteger os cidadãos dos eventuais abusos dos governantes (...) e fornecer aos cidadãos as informações necessárias para o desempenho de suas responsabilidades cívicas, tornando central o conceito de serviço público como parte da identidade jornalística. (TRAQUINA, 2012, p.50)
\end{abstract}

O episódio Watergate ilustra claramente a atuação da imprensa como denunciadora de escândalos políticos. Trata-se do caso de escuta ilegal ocorrido na sede do partido democrata em Washington, nos Estados Unidos, que resultou na renúncia do presidente Nixon.

\footnotetext{
${ }^{7}$ Penny Press modelo de imprensa norte-americana do Séc. XIX, baseada na venda de jornais populares (penny papers), no valor de um centavo, de caráter informativo. (SHUDSON, 2010)

${ }^{8}$ Cabe ressaltar que por não corroborar com o objetivo deste estudo, não serão evidenciadas discussões sobre a objetividade no fazer jornalístico. Nossa proposta, como enfatizado, é apenas contextualizar a visão de imprensa como quarto poder.
} 


\section{Obevisto}

ISSN n² 2447-4266

Vol. 4, n. 2, Abril-Junho. 2018

DOI: http://dx.doi.org/10.20873/uft.2447-4266.2018v4n2p756

Em artigo publicado no Observatório da Imprensa ${ }^{9}$, em 2014, Otavio Farias Filho destaca o caso como impulsionador do jornalismo investigativo no mundo.

É tão profunda a marca deixada pelo caso Watergate que o nome se tornou sinônimo de escândalo político, além de exemplo máximo de jornalismo investigativo (...). Desde então, jornalistas em todo o mundo se inspiram no modelo profissional que os repórteres Carl Bernstein e Bob Woodward encarnaram na trabalhosa apuração que se estendeu por mais de dois anos, entre a publicação da primeira reportagem e a queda de Richard Nixon, em agosto de 1974. A atitude inquisitiva diante da autoridade pública, o recurso a fontes não identificadas (e a regra de exigir pelo menos duas delas para confirmar cada informação), o uso maciço do telefone e do bloco de anotações, a obrigação de se apresentar como jornalista, o intercâmbio de pistas com policiais e promotores, o dever de registrar a versão da parte acusada - nada disso foi inventado pelos dois repórteres, mas se tornou canônico em jornalismo depois do caso Watergate. (FARIAS FILHO, 2014, p.1)

No Brasil, este efeito provocado pelo episódio Watergate no jornalismo foi adiado devido à Ditadura Militar, período marcado pela repressão de qualquer ato investigativo por parte dos jornalistas. Assim, a redemocratização

coincidiu com uma mudança no perfil das redações, com o aumento da presença de jovens da classe média formados em faculdades de jornalismo. Houve uma renovação no jornalismo de resistência à ditadura militar, que teve como marco a cobertura da campanha pelas "Diretas, Já". O País já era outro e a imprensa também. Alguns escândalos pipocavam aqui e acolá, mas eram secundários num trabalho que focava mais os bastidores da política. (FORTES, 2005, p. 77)

A partir de então, o jornalismo brasileiro passou a realizar uma cobertura mais aprofundada dos fatos públicos, cumprindo um dever essencial à sociedade, de fiscalizar os poderes.

\footnotetext{
${ }^{9}$ http://observatoriodaimprensa.com.br/
} 


\section{Grevisto}

ISSN n² 2447-4266

Vol. 4, n. 2, Abril-Junho. 2018

DOI: http://dx.doi.org/10.20873/uft.2447-4266.2018v4n2p756

\section{Jornalismo Investigativo e Accountability}

O termo inglês accountability não encontra tradução certa para o português, porém é entendido como prestação de contas, ou seja, a capacidade que os representantes públicos têm de atender aos anseios da população. (DUTRA E GENTILLI, 2012)

Como afirma Maia:

A questão da accountability é fundamental para a qualificação da democracia moderna. Ela acarreta para os representantes políticos, na organização de seus poderes e obrigações, o dever de responder aos cidadãos, de replicar às críticas a eles endereçadas e de aceitar (alguma) responsabilidade sobre suas falhas, incompetência ou desonestidade. (MAIA, 2006, p. 2)

Assim sendo, mecanismos de accountability permitem aos cidadãos maior controle sobre as ações do governo, gerando responsividade por partes deste.

O jornalismo, principalmente o investigativo, é um dos atores sociais disseminadores da accountability. Ao averiguar e apresentar escândalos que vão de encontro ao bem comum, assim como transgressões e abusos de poder, a imprensa cobra dos agentes públicos respostas por seus atos.

É nesta perspectiva que Waisbord (2000) caracteriza jornalismo investigativo como divulgador de informações, no formato de reportagem, que evidenciam atos de instituições governamentais ou empresas privadas que sejam lesivos ao interesse público e afetem de forma negativa a sociedade.

Do ponto de vista ético, o jornalismo investigativo traz específicas discussões como, por exemplo, as relativas ao que é ou não de interesse público. 


\section{Grevisto}

ISSN n² 2447-4266

Vol. 4, n. 2, Abril-Junho. 2018

DOI: http://dx.doi.org/10.20873/uft.2447-4266.2018v4n2p756

Outros questionamentos éticos também devem estar presentes: a sociedade vai se beneficiar com 0 resultado das reportagens investigativas? Qual deve ser o comportamento do repórter investigativo, já que muitas vezes seu trabalho está situado na fronteira entre 0 direito à privacidade e o direito de informação da sociedade? Quais são os interesses afetados com a divulgação da reportagem investigativa? A enumeração dessas questões aponta que a construção dos critérios de noticiabilidade no jornalismo investigativo está, imperativamente, inserida nas discussões sobre ética profissional e responsabilidade social da imprensa. (AGUIAR, 2006, p. 75)

Sobre o papel deste jornalismo, Sequeira destaca a compreensão de Lage (2001), caracterizando-o como "guardião da sociedade, aquele tipo de jornalismo que visa evidenciar as misérias presentes ou passadas de um corpo social, num esforço para contar os fatos como eles são, foram ou deveriam ter sido". (SEQUEIRA, 2005, p. 24)

Ele destaca ainda a obrigação do jornalista de possuir provas documentais antes da denúncia deste tipo de situações. "Um trabalho completo de documentação, antes do início da apuração, permitirá ao repórter avançar com maior segurança pelo escorregadio mundo dos informantes". (SEQUEIRA, 2005, p. 93)

Corroborando com o autor, Fortes (2005) destaca a definição do jornalista Marcelo Beraba, ex-presidente da Abraji, sobre jornalismo investigativo. De acordo com ele, a atividade "tornou-se uma qualificação específica para as reportagens de mais fôlego, de maior investimento de apuração. Aquela que exige mais tempo e paciência para pesquisas, entrevistas, observação direta, checagem e rechecagem". (FORTES, 2005, p. 14)

Como afirma Macet, os passos iniciais para uma investigação se apoiam sempre em dados sobre o assunto a ser explorado.

El estudio exhaustivo de los archivos públicos, a pesar de ser una tarea difícil, dadas las dificultades burocráticas existentes en la actualidad, 


\section{Grevisto}

ISSN n² 2447-4266

Vol. 4, n. 2, Abril-Junho. 2018

DOI: http://dx.doi.org/10.20873/uft.2447-4266.2018v4n2p756

es un vehículo adecuado para analizar posibles temas de investigación (...) La consulta de los archivos permite acceder a datos registrados sobre actuaciones públicas que inicialmente no levantan las sospechas pero que, tras un pormenorizado análisis, pueden ofrecer pistas interesantes para la investigación. (MACET, 1997, p. 145)

Após a explanação teórica sobre acesso à informação e jornalismo, fica clara a importância do acesso a dados públicos para a concretização de trabalhos jornalísticos de cunho investigativo, como será exemplificado a seguir.

\section{ESTUDO DE CASO DE USO DE INFORMAÇÕES PÚBLICAS POR JORNALISTAS INVESTIGATIVOS}

Exibido pela primeira vez no dia 02 de novembro de 2014, no programa Fantástico da Rede Globo, o quadro "Cadê o dinheiro que tava aqui?" tem como foco principal investigações sobre roubo do dinheiro público.

As denúncias podem ser feitas por internautas de qualquer cidade do Brasil, através do site do programa. Dentre as principais abordagens estão investigações sobre corrupção, empresas de fachada, notas frias e preços superfaturados.

A série de reportagens é produzida pelo jornalista Eduardo Faustini, "o Repórter Secreto", que faz questão de não exibir seu rosto, a fim de preservar sua integridade física.

Faustini explica que a não exposição da sua identidade nas matérias que produz, faz com que o mesmo possa se passar por quem quiser. "Eu protejo a minha próxima matéria e não a minha vida. Uma hora eu posso ser médico, empresário, político (...) O fato de não aparecer é para proteger o trabalho". (CARNEIRO, 2014, p.33) 


\section{Grevisto}

ISSN n² 2447-4266

Vol. 4, n. 2, Abril-Junho. 2018

DOI: http://dx.doi.org/10.20873/uft.2447-4266.2018v4n2p756

Faustini é um dos mais premiados repórteres investigativos da Rede Globo. Em 2013, recebeu o Grande Prêmio Barbosa Lima Sobrinho da Embratel e o Prêmio ETCO de Telejornalismo, com a série de reportagens "A cara da corrupção", que denunciou empresas fictícias que participaram de licitações com cartas marcadas para fugir da fiscalização do governo. A reportagem "Máfia das funerárias" arrebatou o troféu Tim Lopes, em 2007. A matéria denunciava o golpe do atestado de óbito comprado, que envolve agências funerárias e médicos desonestos. Em 2005 foi vencedor do XXII Prêmio Direitos Humanos de Jornalismo, com a matéria "Documentos Queimados", sobre documentos do período da Ditadura Militar que foram encontrados queimados no lixo de uma Base Militar de Salvador. Também recebeu o Prêmio Imprensa Embratel (2004) e o Prêmio Esso Especial de Telejornalismo (2002).

\section{Desvio de dinheiro público no interior do Ceará}

No dia 09 de novembro de 2014, foi exibida a segunda matéria da série sobre denúncias de fraudes em licitações pelas prefeituras de Crato e Juazeiro do Norte, no Ceará.

A reportagem, editada por Toni Marques, com imagens produzidas por Luiz Cláudio Azevedo, retrata casos de empresas de fachada que prestavam serviços de fornecimento de merenda escolar e manutenção de equipamentos hospitalares. Os empreendimentos, juntos, possuíam contratos de mais de $\mathrm{R} \$$ 1,5 milhões. 


\section{Revisto}

ISSN n० 2447-4266

Vol. 4, n. 2, Abril-Junho. 2018

DOI: http://dx.doi.org/10.20873/uft.2447-4266.2018v4n2p756

Na matéria, Eduardo Faustini também não expõe seu rosto, porém, ele mesmo entrevista alguns personagens, ocultando sua voz, conforme imagem abaixo.

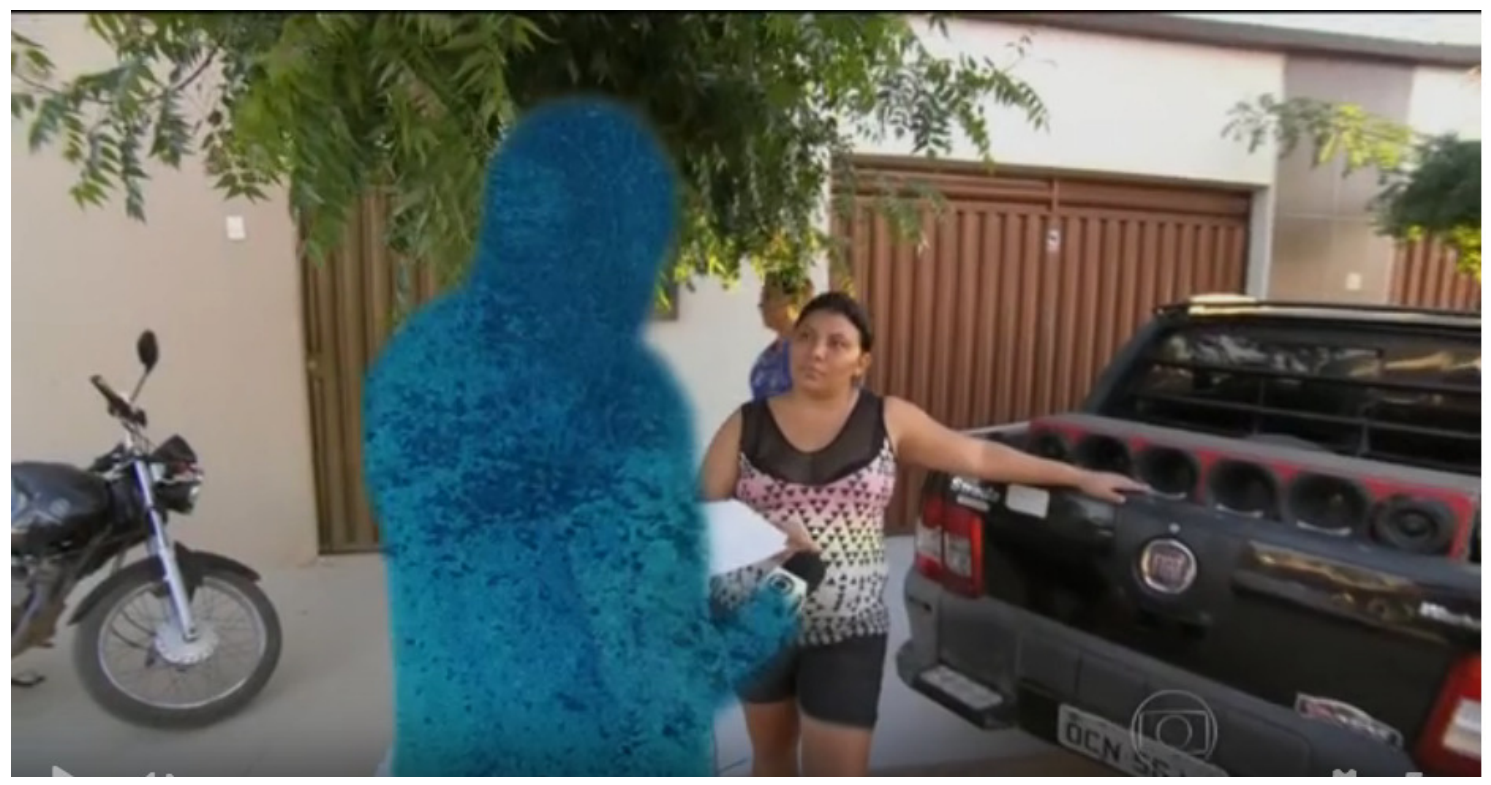

Figura 1: Take da reportagem exibida pelo Fantástico em 09/11/2014, na série "Cadê o dinheiro que tava aqui?" Entrevista de Eduardo Faustini com acusada de fraude em licitações.

Fonte: Youtube: https://www.youtube.com/watch?v=fqWMIA4oHMk. Acesso em 11.abril.2016.

Há, em outros depoimentos de personagens exibidos, indícios de utilização de câmera oculta pelo repórter, conforme a figura abaixo. 


\section{Qbevisto}

ISSN n² 2447-4266

Vol. 4, n. 2, Abril-Junho. 2018

DOI: http://dx.doi.org/10.20873/uft.2447-4266.2018v4n2p756

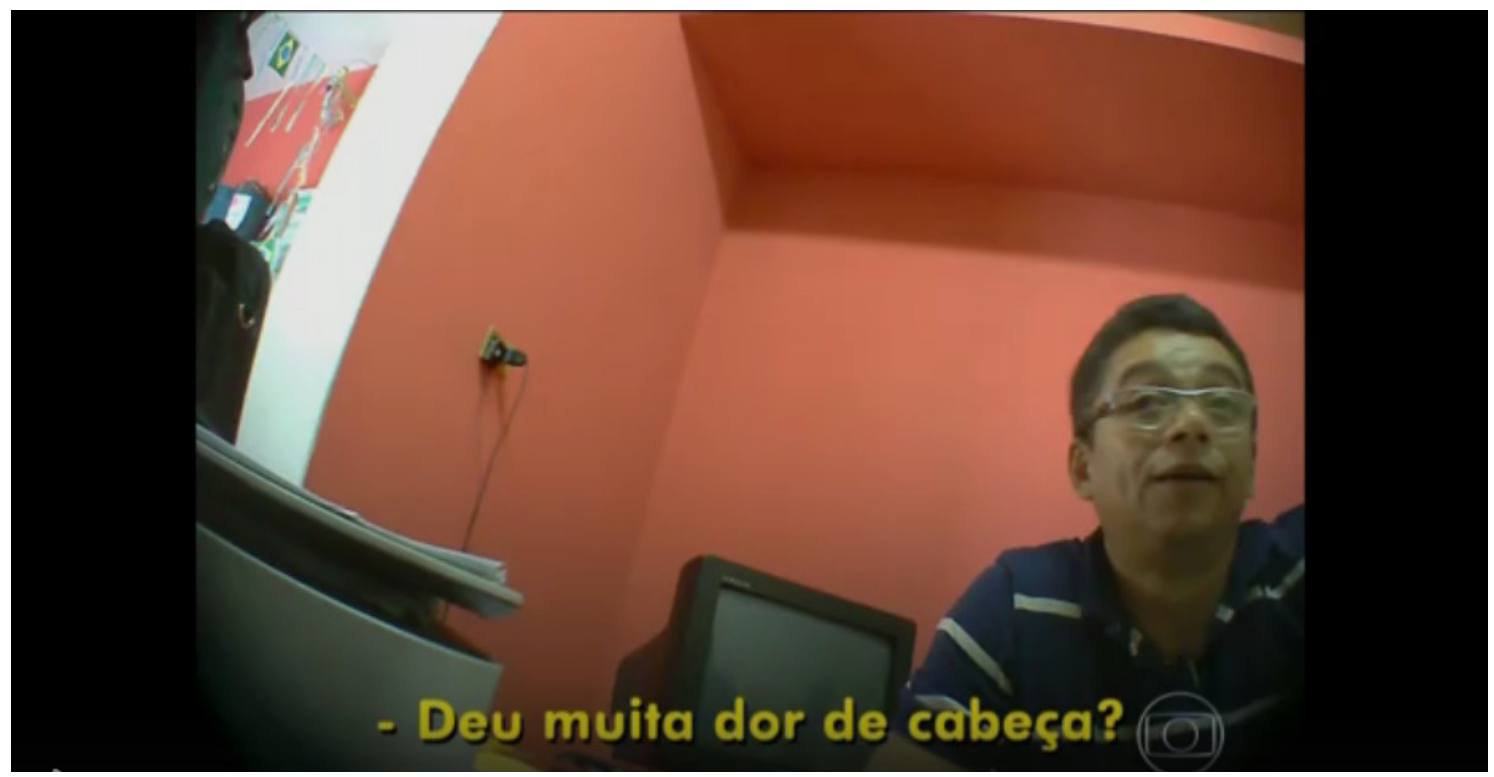

Figura 2: Take da reportagem exibida pelo Fantástico em 09/11/2014, na série "Cadê o dinheiro que tava aqui?" Entrevista com acusado de fraude em licitações.

Fonte: Youtube: https://www.youtube.com/watch?v=fqWMIA4oHMk. Acesso em 11.abril.2016.

Sobre o uso desta ferramenta, Faustini afirma que

... a câmera oculta te dá uma verdade profunda, uma situação que não vai se revelar em frente a uma câmera aberta. No telejornalismo, não consigo fazer a denúncia se não mostrar, e o telespectador quer ver. Estamos falando de situações de denúncia, não do factual (CARNEIRO, 2014, p. 34).

Porém, de acordo com ele, apesar de considerar a utilização de câmara oculta essencial para o seu trabalho, o repórter faz algumas ponderações sobre a ferramenta, considerando-a, muitas vezes um "voo cego". "Você não sabe se está gravando ou não. Se houver a mínima possibilidade de fazer a reportagem sem a microcâmera, a gente abre mão do equipamento (...) É o último recurso que nós utilizamos". (CARNEIRO, 2014, p. 34) 


\section{Crevisto}

ISSN n² 2447-4266

Vol. 4, n. 2, Abril-Junho. 2018

DOI: http://dx.doi.org/10.20873/uft.2447-4266.2018v4n2p756

Diante do exposto, a utilização do recurso de câmera oculta pelo repórter alinha-se às conclusões de Lopes (2003), ao destacar que o jornalista investigativo deve se munir de provas documentais antes da denúncia que será publicada. No caso da reportagem analisada, além dos depoimentos colhidos (com e sem o uso de câmeras ocultas), Faustini utiliza documentos e relatórios sobre o caso destacado.

Como fontes, o Repórter Secreto utilizou populares que necessitavam dos serviços nas áreas de saúde e educação; autoridades envolvidas, como exprefeitos e secretários; assim como informações públicas do Ministério Público, Controladoria Geral da União e Câmara de Vereadores de Juazeiro do Norte, conforme descrito na tabela abaixo.

\begin{tabular}{|ccc|}
\hline ÓRGÃO & FONTE & INFORMAÇÃO \\
\hline $\begin{array}{c}\text { CONTROLADORIA-GERAL } \\
\text { DA UNIÃO }\end{array}$ & $\begin{array}{c}\text { Relatório de Fiscalização No } \\
38011 \text { de } 04 / 03 / 2013^{10}\end{array}$ & $\begin{array}{c}\text { Empresas vencedoras de } \\
\text { Pregão Presencial para } \\
\text { fornecimento da merenda } \\
\text { escolar no Crato (CE) com } \\
\text { características de empresas } \\
\text { de fachada. }\end{array}$ \\
\hline $\begin{array}{c}\text { MINISTÉRIO PÚBLICO } \\
\text { FEDERAL NO CEARÁ (MPF) }\end{array}$ & Procurador Rafael Rayol & $\begin{array}{c}\text { Preços contratados e pagos } \\
\text { pela prefeitura de Juazeiro do } \\
\text { Norte estão superfaturados } \\
\text { em mais de R\$ } 350 \text { mil. }\end{array}$ \\
\hline $\begin{array}{c}\text { CÂMARA MUNICIPAL DE } \\
\text { JUAZEIRO DO NORTE }\end{array}$ & Vereador Cláudio Luz/ & $\begin{array}{c}\text { A empresa de manutenção de } \\
\text { equipamentos hospitalares } \\
\text { não possuía sede própria e só } \\
\text { comercializava a nota fiscal } \\
\text { para comprovação das } \\
\text { compras. }\end{array}$ \\
\hline
\end{tabular}

Tabela 2: Dados oficiais obtidos para produção da matéria. FONTE: Elaboração própria.

10 Disponível em <http://sistemas2.cgu.gov.br/relats/uploads/RM38011-CE-\%20Crato.pdf>. Acesso em 21.dez.2015. 


\section{Grevisto}

ISSN n² 2447-4266

Vol. 4, n. 2, Abril-Junho. 2018

DOI: http://dx.doi.org/10.20873/uft.2447-4266.2018v4n2p756

Em relação ao acesso às informações públicas utilizadas pelo repórter, têm-se as seguintes considerações:

- Todo o conteúdo apresentado na matéria é considerado de total interesse público, portanto passível de publicação, conforme a Lei de Acesso. As informações expostas também não são caracterizadas como sigilosas ("aquelas submetidas temporariamente à restrição de acesso público em razão de sua imprescindibilidade para a segurança da sociedade e do Estado"), nem pessoais ("relacionadas à pessoa natural identificada ou identificável"), como explicitam os incisos III e IV do Artigo $4^{\circ}$ da LAI.

- Dentre as diretrizes contidas no Artigo $3^{\circ}$ do dispositivo legal, as instituições que foram fontes de informação para a produção da reportagem (CGU, Ministério Público Federal e Câmara Municipal de Juazeiro do Norte) cumpriram:

"I - observância da publicidade como preceito geral e do sigilo como exceção", uma vez que as fontes procuradas disponibilizaram as informações solicitadas;

"Il - divulgação de informações de interesse público, independentemente de solicitações e III - utilização de meios de comunicação viabilizados pela tecnologia da informação". Estes princípios, assim como o que dispõe o Artigo $8^{\circ}$, tratam da disponibilização de conteúdos de interesse público em locais de fácil acesso. No caso, a Controladoria Geral da União publicou, em seu site, o relatório de fiscalização que trata dos resultados dos exames realizados sobre 11 Ações de Governo integrantes dos Programas fiscalizados, executadas no município de Crato - CE. Tais documentos são base da denúncia apresentada pelo Fantástico e correspondem ao exposto no Artigo $7^{\circ}$, Inciso VII, b., que trata da disponibilização de "resultado de inspeções, auditorias, prestações e 


\section{Grevisto}

ISSN n² 2447-4266

Vol. 4, n. 2, Abril-Junho. 2018

DOI: http://dx.doi.org/10.20873/uft.2447-4266.2018v4n2p756

tomadas de contas realizadas pelos órgãos de controle interno e externo, incluindo prestações de contas relativas a exercícios anteriores".

"IV - fomento ao desenvolvimento da cultura de transparência na administração pública". Em entrevista, o Analista em Comunicação do MPF/CE, Walison Costa, informou que a Política de Comunicação do órgão, além de ter como princípios a transparência e a acessibilidade de informações, estabelece que "todos os setores do Ministério Público Federal devem atender às demandas de informações com prontidão" (COSTA, 2016) ${ }^{11}$, seguindo, portanto, o que determina a lei.

- As informações disponibilizadas também estão de acordo com o inciso II, do Artigo $6^{\circ}$, ou seja, tiveram sua disponibilidade, autenticidade e integridade garantidas.

- Sobre a obtenção dos conteúdos, cabe destacar que durante a realização desta pesquisa, não foram encontrados, na Internet, através de buscas simplificadas, os relatórios do Ministério Público e da Câmara Municipal supracitada.

Porém, apesar de não estarem divulgadas em sites oficiais, as conclusões do MPF foram apresentadas na matéria pelo procurador Rafael Rayol, que exibe imagens dos documentos onde constam os dados. Sobre o acesso à documentação pelo repórter, o analista do MPF/CE entrevistado ${ }^{12}$ informou que o órgão disponibilizou à equipe do Fantástico "documentos, depoimentos, procedimentos adotados - e cópias de depoimentos em vídeo gravados pelo MPF".

\footnotetext{
${ }^{11}$ Walison Costa, Analista de Comunicação do MPF/CE. Entrevista realizada via e-mail, em 29.01.2016.

${ }_{12}$ Walison Costa, Analista de Comunicação do MPF/CE. Entrevista realizada via e-mail, em 29.01.2016.
} 


\section{Grevisto}

ISSN n² 2447-4266

Vol. 4, n. 2, Abril-Junho. 2018

DOI: http://dx.doi.org/10.20873/uft.2447-4266.2018v4n2p756

- O depoimento de um dos acusados apresentados à Câmara Municipal de Juazeiro do Norte também foi disponibilizado e exposto pelo vereador Cláudio Luz na matéria. Em entrevista concedida a uma das autoras deste artigo, o parlamentar destacou que esta declaração foi apresentada inicialmente como parte "de uma Comissão Parlamentar de Inquérito instalada a muito custo, na Câmara de Vereadores, e que finalizou com descobertas estarrecedoras de desvio de dinheiro da saúde e educação públicas em Juazeiro do Norte". (LUZ, 2016 $6^{13}$ ) Apesar de apresentar informações exigidas pela LAI (como receitas, despesas, contratos, licitações, programas e projetos), o portal da Câmara ${ }^{14}$ não disponibiliza relatórios das CPIs implantadas. Segundo Cláudio Luz, as informações desta CPI foram encaminhadas, por ele, para o Tribunal de Justiça do Ceará, Ministério Público, Controladoria Geral da União e Polícias Federal e Civil.

\section{CONSIDERAÇÕES FINAIS}

O acesso a documentos e dados de interesse público, apresentados na reportagem do programa Fantástico, foi de suma importância para a realização do trabalho de investigação e a divulgação dos casos de desvio de dinheiro público apontados pelo jornalista Eduardo Faustini.

Conforme evidenciado neste trabalho, o jornalista investigativo é destacado como ator social responsável pela exibição desses conteúdos, principalmente, quando instituições e órgãos, descumprem as determinações da Lei de Acesso, não disponibilizando tais dados via internet.

\footnotetext{
${ }^{13}$ Cláudio Luz, Vereador do Município de Juazeiro do Norte (CE). Entrevista realizada via e-mail, em 06.04.2016.

${ }^{14}$ http://www.camarajuazeiro.ce.gov.br/
} 


\section{Gevisto}

ISSN n² 2447-4266

Vol. 4, n. 2, Abril-Junho. 2018

DOI: http://dx.doi.org/10.20873/uft.2447-4266.2018v4n2p756

Para Faustini, o papel do jornalismo investigativo é justamente o de disponibilizar informações de interesse público. "A intenção do jornalismo investigativo é informar, não é punir e prender. A minha preocupação é a informação. A punição cabe ao Ministério Público". (CARNEIRO, 2014, p. 35)

O vereador Cláudio Luz, personagem da reportagem, corrobora com o jornalista, ao afirmar que o jornalismo investigativo é fundamental para o combate a corrupção.

Acho que o jornalista investigativo é importante, na medida em que, além de obter dados que comprovam a corrupção ele tem acesso ao canal de transmissão dessa informação à sociedade em geral. E quando a informação é revelada publicamente acaba obrigando os órgãos competentes (MP's, polícias, órgãos de controle) a agirem. (LUZ, 2016)

Por fim, conclui-se que o jornalismo investigativo é uma atividade fundamental para a revelação de casos de corrupção. Tal atividade possui como bases primordiais a liberdade de expressão e o livre acesso às informações de interesse público, assegurados pelo dispositivo legal, que traz em seu bojo a garantia de um jornalismo consubstanciado na verdade dos fatos, e alicerçado em prova documental em prol da eficácia de sua informação.

\section{REFERÊNCIAS}

AGUIAR, Leonel. $\mathbf{0}$ jornalismo investigativo e seus critérios de noticiabilidade: notas introdutórias. Revista Alceu. Vol. 7, N. 13. Jul/Dez, 2006. Disponível em http://revistaalceu.com.pucrio.br/cgi/cgilua.exe/sys/start.htm?sid=25. Acesso em 26. mai.2016.

ACKERMAN, J.; SANDOVAL, I. Leyes de Acceso a la Información em el Mundo. Cuadernos de Transparência, n. 7. México: IFAl, 2005. Disponível em: 


\section{Crevisto}

ISSN n² 2447-4266

Vol. 4, n. 2, Abril-Junho. 2018

DOI: http://dx.doi.org/10.20873/uft.2447-4266.2018v4n2p756

$<$ http://www.cdc.gob.cl/wpcontent/uploads/documentos/ackerman \& sandoval laip.pdf. >. Acesso em 17.03.2016.

BRASIL. Constituição (1988). Constituição da República Federativa do Brasil. Brasília, DF: Senado Federal: Centro Gráfico, 1988.

BRASIL. Lei n. ${ }^{\circ} 12.527$, de 18 de novembro de 2011. Dispõe sobre os procedimentos a serem observados pela União, Estados, Distrito Federal e Municípios, com o fim de garantir o acesso a informações previsto na Constituição Federal. Diário Oficial da União, Brasília, 2011.

BRASIL. Cartilha Acesso á Informação Pública: Uma introdução à Lei $\mathbf{n}^{\circ}$ 12.527, de 18 de novembro de 2011. Controladoria-Geral da União. Brasília, 2011. Disponível em http://www.acessoainformacao.gov.br/central-deconteudo/publicacoes/arquivos/cartilhaacessoainformacao.pdf. Acesso em 22 de dezembro de 2015.

CARNEIRO, Isabella. O repórter sem rosto - Análise do trabalho do jornalista Eduardo Faustini com o uso da câmera oculta em reportagens investigativas no programa fantástico, da Rede Globo. Trabalho de Conclusão de Curso apresentado na Faculdade de Comunicação da Universidade de Brasília, 2014.

COSTA, Walison. Entrevista realizada via e-mail. Entrevistador: Verônica Rufino, em 29.jan.2016.

DUTRA, Luma. Direito à informação em pauta: os usos da Lei de Acesso por Jornalistas. (Dissertação de Mestrado). Universidade de Brasília, 2015. Disponível em: <http://repositorio.unb.br/handle/10482/17909>. Acesso em: 01.dez.2015.

FARIAS FILHO, Otavio. Um modelo de jornalismo investigativo. Observatório da Imprensa. Edição 794. Em 25.maio.2014. Disponível em < http://observatoriodaimprensa.com.br/imprensa-emquestao/ed791_um modelo de jornalismo investigativo/> .

FORTES, Leandro. Jornalismo investigativo. São Paulo : Contexto, 2005. 


\section{Crevisto}

ISSN n² 2447-4266

Vol. 4, n. 2, Abril-Junho. 2018

DOI: http://dx.doi.org/10.20873/uft.2447-4266.2018v4n2p756

GENTILLI, Victor. DUTRA, Luma. Direito à Informação: os jornalistas e o estado transparente. In: $10^{\circ}$ Encontro Nacional de Pesquisadores em Jornalismo. Curitiba. Anais... 2012, Curitiba. Disponível em: < http://www.sbpjor.org.br/sbpjor/?p=11689>. Acesso em 30.nov.2015.

LAGE, Nilson. A reportagem: teoria e técnica de entrevista e pesquisa jornalística. Rio de

Janeiro: Record, 2001.

LOPES, Dirceu Fernandes; PROENCA, José Luiz (orgs). Jornalismo investigativo. São Paulo: Publisher Brasil, 2003.

LUZ, Cláudio. Entrevista realizada via e-mail. Entrevistador: Verônica Rufino, em 06.abr.2016.

MACET, José Maria. Periodismo de Investigación. Teoría y Práctica. Editorial Síntesis. Madrid, 1997.

MAIA, Rousiley. Mídia e diferentes dimensões da Accountability. Revista ECompós. Vol.07, 2006. Disponível em http://www.compos.org.br/seer/index.php/e-compos/article/view/113. Acesso em 16.dez.2015.

MAGALHÃES, Roberto. MEDEIROS, Simone. PEREIRA, José Roberto. Lei de Acesso à Informação: Em busca da transparência e do combate à corrupção. Revista Informação, V.19, Londrina, 2014. Disponível em < http://www.uel.br/revistas/uel/index.php/informacao/article/view/13520>.

Acesso em 02.dez.2015.

MENDEL, T. Liberdade de informação: um estudo de direito comparado. Brasília: UNESCO, $2009 . \quad$ Disponível em $<$ http://www.acessoainformacao.gov.br/central-deconteudo/publicacoes/arquivos/liberdade-informacao-estudo-direitocomparado-unesco.pdf> Acesso em 22.02.2016.

RODRIGUES, Vanessa. Direito Fundamental de Acesso a Informações Públicas: Análise do Direito Comparado e da Lei 12.527/2011. Caderno Virtual do Instituto Brasiliense de Direito Público. Vol.1, Brasília, 2012. Disponível

$\mathrm{em}<$ 


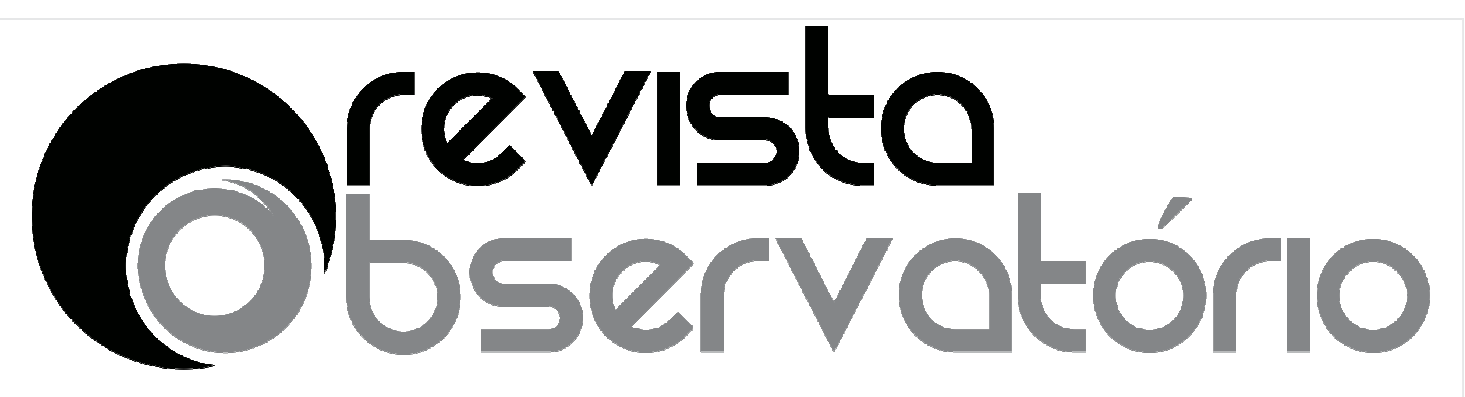

ISSN n² 2447-4266

Vol. 4, n. 2, Abril-Junho. 2018

DOI: http://dx.doi.org/10.20873/uft.2447-4266.2018v4n2p756

http://www.portaldeperiodicos.idp.edu.br/index.php/cadernovirtual/article/view /700/478 >. Acesso em 02.dez.2015.

SCHUDSON, M. Descobrindo a notícia. Petrópolis: Vozes, 2010.

SEQUEIRA, Cleofe. Jornalismo Investigativo. 0 fato por trás da notícia. Summus. São Paulo, 2005.

TRAQUINA, Nelson. Teorias do Jornalismo - Porque As Notícias São Como São - Vol. 1 - 3a Ed. Insular, 2012.

WAISBORD, Silvio. Watchdog journalism in South America: news, accountability and democracy. Nova York: Columbia University Press, 2000. 